\title{
Playing for fun or for profit: how extrinsically-motivated and intrinsically-motivated players make the choice between competing dual-purposed gaming platforms
}

\author{
Esko Penttinen ${ }^{1} \cdot$ Merja Halme $^{1} \cdot$ Pekka Malo $^{1} \cdot$ Timo Saarinen $^{1} \cdot$ Ville-Matias Vilén $^{2}$
}

Received: 16 March 2017 / Accepted: 7 May 2018/Published online: 27 May 2018

(C) The Author(s) 2018

\begin{abstract}
An online poker site is a good example of a dual-purposed information system that is used for both fun and making money. In this study, we address the platform selection problem associated with online poker sites by investigating the features online gamers value when selecting a platform. We test the differences in preferences for online gaming platforms between two types of users: primarily extrinsically-motivated and primarily intrinsically-motivated players. Surprisingly, when comparing the importance scores of the features (usability, enjoyment, functionalities, poker network, loyalty program, and reputation), we observe very little difference between the two user groups. The only difference was that loyalty programs were valued considerably more by extrinsicallymotivated players. One would have expected that features such as functionalities, poker network, and reputation would dominate the choice calculus for extrinsically-motivated players and that features such as usability and enjoyment would dominate the choice calculus for intrinsically-motivated players. We interpret this surprising finding as providing support to the claim that utilitarian and hedonic values are becoming increasingly intertwined. In this article, we provide alternative interpretations for this surprising result and discuss its theoretical and managerial implications. Because this is an exploratory study, we also note several avenues for future research.
\end{abstract}

Key words Extrinsic and intrinsic motivation · Platform selection · Dual-purposed information systems · Online gaming $\cdot$ Conjoint analysis

JEL classification C11 Bayesian Analysis: General · C44 Operations Research: Statistical Decision Theory · C83 Survey Methods: Sampling Methods M00 General

Responsible Editors: Christian Matt and Manuel Trenz

Esko Penttinen

esko.penttinen@aalto.fi

Merja Halme

merja.halme@aalto.fi

Pekka Malo

pekka.malo@aalto.fi

Timo Saarinen

timo.saarinen@aalto.fi

Ville-Matias Vilén

ville-matias.vilen@accenture.com

1 Aalto University School of Business,

Runeberginkatu 14, 00100 Helsinki, Finland

2 Accenture Finland,

Porkkalankatu 5, 00180 Helsinki, Finland

\section{Introduction}

Making choices in the digital environment is becoming increasingly complex due to the proliferation of digital platforms and artifacts that often offer both utilitarian and hedonic value to users (Lee et al. 2005; Turel et al. 2010; Weiss and Schiele 2013). Given this abundance of alternatives available for individuals and the large variety of use situations and motivations, it is of paramount importance to determine how individuals make choices in digital environments, i.e., how they make a selection among competing platform providers and digital artifacts. Most of the extant literature addressing the various aspects of information systems (IS) use (such as assimilation, adoption, deployment, and continued use) has focused on utilitarian systems and outlined the salient factors that explain system use. Only relatively recently, researchers 
developed models to improve our understanding of hedonic systems use (Lowry et al. 2013; van der Heijden 2004; Wu and $\mathrm{Lu} \mathrm{2013).} \mathrm{It} \mathrm{has} \mathrm{been} \mathrm{argued} \mathrm{that} \mathrm{extrinsic} \mathrm{motivation}$ drives the use of utilitarian systems and that intrinsic motivation drives the use of hedonic systems (Babin et al. 1994). Extrinsic motivation stems from the instrumental benefit of usage through goal-driven actions. However, intrinsic motivation involves engaging in a behavior for its own sake - out of interest or for the pleasure and inherent satisfaction derived from the experience (Lee et al. 2005; Wu and $\mathrm{Lu} 2013$ ).

Increasingly, the intrinsic and extrinsic motivations to use systems are intertwined, meaning that many IS are used to fulfill a mixed range of needs and wants, which has led to the emergence of studies on dual-purposed IS (Verhagen et al. 2012; Wu and Lu 2013). Dual-purposed systems are used for both productivity (utilitarian purposes) and pleasure (hedonic purposes). Examples addressed in previous literature include email systems, the Internet, and mobile communication technologies (Wu and $\mathrm{Lu}$ 2013). Because of the increasing importance of dual-purposed systems, a new set of research problems arises: given that users of dual-purposed systems are heterogeneous in their motivations, how should these systems be designed to cater to different motivations (extrinsic and intrinsic)? In this article, we study online gamers and their selection of a site, i.e., a platform, ${ }^{1}$ to play poker on the Internet. An online poker site is an excellent example of a system that can be used either for fun or to make money. Both the utilitarian and hedonic values have an impact when users play games on these sites. Motivated by this interesting empirical setting and by a lack of understanding in the current literature related to the potential differences in preferences across the two user groups, we address the following research question: "What are the differences between primarily extrinsically-motivated users and primarily intrinsically-motivated users in terms of their selection of online platforms?" In essence, we are interested in determining whether extrinsically-motivated users value some platform features differently from how intrinsicallymotivated users value these features.

Instead of studying the awareness and adoption phases of the IS assimilation process (Bala and Venkatesh 2007), we study the deployment phase. We focus on the decision of selecting a platform for IS usage (for either primarily utilitarian or primarily hedonic purposes) in a specific situation. We do not study the initial adoption factors associated with IS use; therefore, we do not make knowledge claims on any issues related to adoption. Instead, in our study, the users have already made the adoption decision, and we empirically focus

\footnotetext{
${ }^{1}$ We use the terms 'online gaming internet site' and 'online gaming platform' interchangeably in this paper. An online poker gaming site is essentially a platform (Eisenmann et al. 2006) that allows multiple gamers to play on an internet website. It is categorized as a one-sided platform, similar to an instant messaging platform where most of the value is derived from a single class of users (in this case poker players).
}

on the decision-making problem associated with choosing the preferred electronic platform.

We develop a research instrument based on relevant literature on technology assimilation and platforms enriched by indepth interviews with online poker players. The final version of our model included the following features that may affect the choice of an online poker platform: 1) Usability, 2) Enjoyment, 3) Functionalities, 4) Poker network, 5) Loyalty program, and 6) Reputation. We collected data from 332 online poker players via a web site call-for-participation and probed the importance of these features on customer choice. Our sample included 222 primarily extrinsically-motivated gamers and 110 primarily intrinsically-motivated gamers. Choice-based conjoint analysis was used as the preference elicitation model. Unlike survey instruments based on Likert scales, we believe that conjoint analysis is particularly useful for studying the platform selection problem as it presents realistic choice tasks to the respondent and requires him/her to make trade-offs between features.

Although our aim was not to identify and validate the most salient features of online gaming sites, we did find that all six features were statistically significant in the aggregate level model for explaining the platform choice problem. Still outside the scope of our study, our analyses revealed that the ranking of the importance of features in the sample was as follows: reputation, size of network, loyalty programs, enjoyment, usability and functionalities. Regarding our research question, the comparison of the importance of the features between extrinsicallymotivated players and intrinsically-motivated players revealed an interesting similarity in terms of platform feature preferences: the only feature that differed between the two user groups was "loyalty programs," which was more important to extrinsically-motivated gamers. This unexpected result of only minor differences between the two gamer groups is discussed, and alternative interpretations of our results are explored in the last part of the paper. We hope this exploratory study and discussion facilitates more research on the similarities and differences among different types of users.

\section{Extrinsic and intrinsic motivations and online poker}

Understanding the intertwining nature of utilitarian and hedonic consumer values is vital, as these values have important implications for consumer behavior (Hirschman and Holbrook 1982), product design (Chitturi et al. 2008), brand attitude (Voss et al. 2003), shopping value (Babin et al. 1994), IS adoption (van der Heijden 2004), and systems design and development (Park and Sawy 2008). Next, we turn to relevant literature on motivations (extrinsic and intrinsic) and system types (utilitarian, hedonic, and dual-purposed information systems). Then, we discuss online platforms and consumer 
selection, noting considerable lack of research probing the factors impacting consumers' choice calculus. We conclude our literature review with a section articulating the inherent characteristics of online poker, establishing the associated online poker platforms as dual-purposed information systems.

\section{Extrinsic and intrinsic motivation to use dual-purposed information systems}

Utilitarian value includes the functional, instrumental, and practical benefits of the consumption offering, whereas hedonic value includes the aesthetic, experiential, and enjoyment-related benefits (Chitturi et al. 2008). Consumers purchase goods and services and engage in consumption behaviors for two basic reasons: (1) consummatory, affective (hedonic) gratification (from sensory attributes), and (2) instrumental, utilitarian gain (Batra and Ahtola 1990). In the field of marketing, scholars have developed scales to measure the hedonic and utilitarian dimensions of consumer value and brand/product attitudes (Batra and Ahtola 1990; Voss et al. 2003). These dimensions include aspects such as effective/ ineffective, helpful/unhelpful, functional/not functional, necessary/unnecessary, and practical/impractical for the utilitarian dimension and items such as fun/not fun, exciting/dull, delightful/not delightful, thrilling/not thrilling, and enjoyable/unenjoyable for the hedonic dimension (Voss et al. 2003). These dimensions resonate well with the extrinsic and intrinsic motivations employed in the IS literature by $\mathrm{Wu}$ and $\mathrm{Lu}$ (2013): perceived usefulness, job relevance, image, affiliation motivation, reward, and punishment for extrinsic motivations as well as enjoyment, flow, playfulness, pleasure, and arousal for intrinsic motivations.

Naturally, these utilitarian and hedonic consumer value dimensions are reflected in IS design. Some IS are clearly geared towards fulfilling hedonic requirements, whereas others are designed to fulfill utilitarian purposes (Park and Sawy 2008; van der Heijden 2004). Typical examples include enterprise resource planning systems (ERPs) for utilitarian purposes and computer games for hedonic purposes. Hedonic systems aim to provide self-fulfilling value to the user, in contrast to utilitarian systems, which aim to provide instrumental value to the user (van der Heijden 2004). Utilitarian systems focus on efficiency, leading to productive use as the main design objective. Conversely, the main design objective of hedonic systems is to encourage prolonged use ( $\mathrm{Li}$ et al. 2015).

Located in the intersection of utilitarian and hedonic systems, dual-purposed information systems (also labeled in extant literature as mixed or multipurpose information systems) are systems that provide both utilitarian and hedonic value to their users (Verhagen et al. 2012). It is challenging to make a clear demarcation between utilitarian, dual-purposed, and hedonic information systems, however, the figure below (Fig. 1) makes an attempt to map these three types of information systems to the motivation types (extrinsic and intrinsic) discussed above. While previous research has found that extrinsic motivation drives the use of utilitarian systems and intrinsic motivation the use of hedonic systems (Wu and $\mathrm{Lu} 2013$ ), we find increasing evidence of these motivations being intertwined. This is evidenced by some recent studies highlighting the importance of intrinsic motivation for even the most utilitarian systems (Gerow et al. 2013). Similarly, in hedonic settings, systems would benefit from features geared towards ensuring a high level of extrinsic motivation (Verhagen et al. 2012).

In the realm of dual-purposed information systems, prior literature has addressed the interrelated nature of extrinsic and intrinsic motivations to use such systems (Table 1). Drawing on an extensive meta-analysis of utilitarian, hedonic, and dualpurposed information systems examined in prior literature, $\mathrm{Wu}$ and $\mathrm{Lu}$ (2013) found extrinsic and intrinsic motivators to evenly share predictive power to explain intention and actual usage of dual-purposed information systems. Studying virtual worlds as dual-purposed systems, Verhagen et al. (2012) highlighted the interrelatedness of extrinsic and intrinsic motivations and found perceptions of economic value, ease of use and escapism to drive both extrinsic and intrinsic motivation to spend time in virtual worlds. This interrelatedness of extrinsic and intrinsic motivations was supported in a case study on crowdsourcing, where Soliman and Tuunainen (2015) found the main drivers of crowdsourcing to be a mix of extrinsic and intrinsic motivations. Closer to our primary research question concerning the different types of users on dual-purposed information systems, Gu et al. (2010) studied instant messaging and identified primarily extrinsically-motivated users (employees) and primarily intrinsically-motivated (students) users. Their study revealed differences across the two user groups: employees were strongly affected by utilitarian usefulness, while students were more greatly affected by hedonic usefulness.

While we acknowledge that there are numerous empirical studies on systems that are used for both utilitarian and hedonic purposes, here we focus on papers that discussed specifically dual-purposed information systems (also labelled as mixed or multipurpose information systems) and/or identified primarily extrinsically- or intrinsically-motivated user groups. For a more complete literature listing of studies on utilitarian, hedonic, and dual-purposed information systems, we guide the reader to the meta-analyses provided in $\mathrm{Wu}$ and $\mathrm{Lu}$ (2013) and Gerow et al. (2013).

\section{Online platforms and consumer selection - Uncharted territory}

Increasingly, instead of distinct and separate IS, information goods and services are consumed through platforms (Eisenmann et al. 2006; Haile and Altmann 2016) where consumers and service providers (or consumers and consumers) 


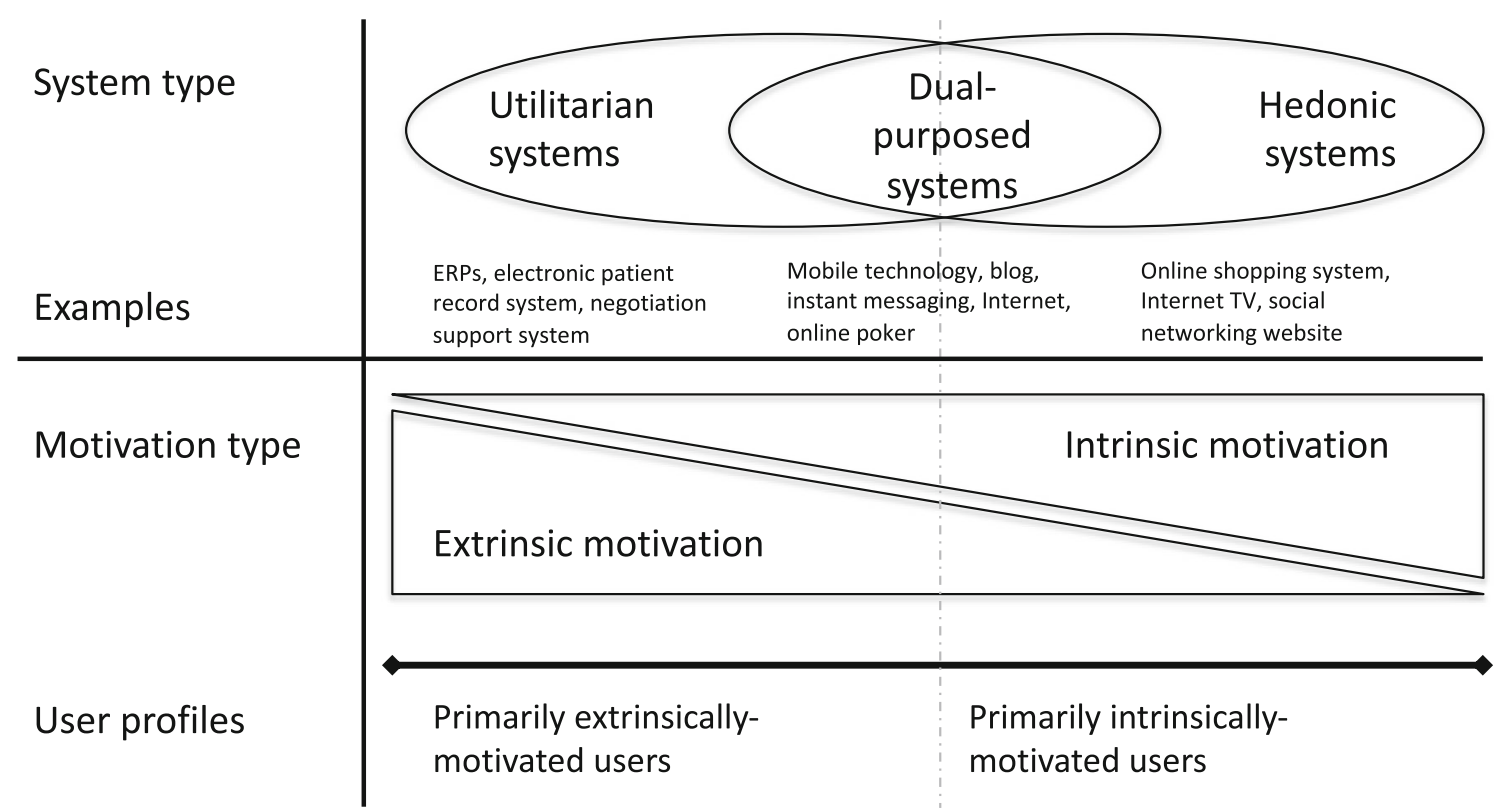

Fig. 1 Extrinsic and intrinsic motivation and types of information systems

interact to create value. Many of these platforms operate in a virtual space, such as online platforms accessible through the Internet. Recently, many types of platforms have emerged across industries enabling a wide range of interactions on platforms. Thus far, researchers have spent considerable effort in seeking to understand conditions that promote fast platform growth and underlie successful marketing strategies. The seeding strategy (Parker et al. 2016) and staged strategy (Hagiu and Eisenmann 2007) aim to create value units that are relevant to at least some users of the platform from the outset. When these users become attracted to the platform, other users will follow. Other strategies focus on subsidies and product giveaways (Eisenmann et al. 2006; Parker and Van Alstyne 2005), which create traction and provide financial incentives to some users of the platform that also attract other users. The marquee strategy focuses on key users. The participation of these users is deemed so important that their participation will make or break the growth of the platform (Parker et al. 2016). Through

Table 1 Studies on extrinsic and intrinsic motivation of dual-purposed information systems

\begin{tabular}{|c|c|c|c|}
\hline Source & System & Method & Main findings \\
\hline (Gerow et al. 2013) & Multiple (review) & $\begin{array}{l}\text { Meta-analysis of } \\
\text { existing research }\end{array}$ & $\begin{array}{l}\text { Intrinsic motivation is important to understanding individuals' } \\
\text { interaction with all types of information systems (utilitarian, } \\
\text { hedonic, and mixed). }\end{array}$ \\
\hline (Gu et al. 2010) & Instant messaging & $\begin{array}{l}\text { Structural equation } \\
\text { modeling }\end{array}$ & $\begin{array}{l}\text { Importance of utilitarian and hedonic factors is perceived } \\
\text { differently by different groups of users. Dual-purposed infor- } \\
\text { mation systems should provide both hedonic and utilitarian } \\
\text { features. }\end{array}$ \\
\hline (Hong and Tam 2006) & Mobile data services & $\begin{array}{l}\text { Structural equation } \\
\text { modeling }\end{array}$ & $\begin{array}{l}\text { Determinants of multipurpose information appliance adoption } \\
\text { decisions are not only different from those in the work place, } \\
\text { but also dependent on the nature of the target technology and } \\
\text { its usage context. }\end{array}$ \\
\hline (Soliman and Tuunainen 2015) & Crowdsourcing & Case study & $\begin{array}{l}\text { Main drivers of crowdsourcing were found to be a mix of both } \\
\text { extrinsic (monetary reward, developing one' skill and career, } \\
\text { and publicity) and intrinsic (curiosity, enjoyment, and altruism) } \\
\text { motivational factors. }\end{array}$ \\
\hline (Verhagen et al. 2012) & Virtual worlds (VW) & $\begin{array}{l}\text { Structural equation } \\
\text { modeling }\end{array}$ & $\begin{array}{l}\text { Highlighted the interrelatedness of extrinsic and intrinsic } \\
\text { motivations. } \\
\text { Perceptions of economic value, ease of use and escapism drive } \\
\text { both extrinsic and intrinsic motivation to use VW. }\end{array}$ \\
\hline (Wu and $\mathrm{Lu} 2013$ ) & Multiple (review) & $\begin{array}{l}\text { Meta-analysis of } \\
\text { existing research }\end{array}$ & $\begin{array}{l}\text { In dual-purposed systems, extrinsic and intrinsic motivators } \\
\text { evenly share predictive power, they nearly "average out". }\end{array}$ \\
\hline
\end{tabular}


platform envelopment (Eisenmann et al. 2011), an orchestrator in one market can enter other markets by combining the functionalities of the platform with that of the target platform and hence create a multi-platform hybrid that leverages the shared user base and the relationships of the users.

All these strategies aim to fuel positive network effects. However, the other end influencing the growth logic largely remains unstudied: what makes platform customers select between competing platforms, what factors influence their choices, and how do various user groups differ in their preferences? Two main types of consumers exist for these platforms: those who seek primarily utilitarian value and those who seek hedonic value, which makes designing the platform more complex than developing IS specific to each user type because the platform provider must cater to both the need for instrumental value for utilitarian reasons and the need for selffulfilling value for hedonic reasons. A question then arises: do differences exist between the two types of consumers (extrinsically-motivated and intrinsically-motivated) in their platform selection? Selecting a platform is an inherently different problem from selecting an information system for performing a task (whether utilitarian or hedonic), as the platform selection problem portrays a more nuanced choice problem incorporating choice factors, such as network effects, in addition to traditional factors related to usability, usefulness and enjoyment. Surprisingly, we found no previous research that addressed consumer platform selection in general (for a recent study in organizational setting, see Penttinen et al. 2018) or the problem of comparing two distinct user types and specifically, extrinsically-motivated and intrinsically-motivated users.

\section{Utilitarian vs. hedonic poker play}

A great debate has been ongoing regarding whether poker is a game of skill or luck. ${ }^{2}$ More precisely, the question is whether poker is a game where skill has more impact than luck or vice versa. One recent study conducted by Hannum and Cabot (2009) attempts to provide unambiguous evidence that poker truly is a game dominated by skill rather than by luck. Poker is played against other individual players instead of against the casino; therefore, skills may have an impact on the game. The authors argue that poker requires skills in mathematics, psychology, evaluating competition, and fund management. According to the study, practicing poker will increase one's skill level against other players. In addition, they claim that in a game of pure luck, a player cannot lose or lose faster because of intentionally poor performance, which is possible in games of skill.

Another recent study by McCormack and Griffiths (2012) attempts to provide an explanation for a fairly new phenomenon: some users earn their living by playing poker. The authors

\footnotetext{
${ }^{2}$ Appendix 1 provides a factsheet on poker, alternative ways of playing poker and information regarding the emergence of online poker.
}

attempt to explain the differences between the behavior and attitudes of professional (extrinsically-motivated) and recreational (intrinsically-motivated) poker players. The results of the study suggested that playing poker for a living is possible but requires a set of specific characteristics. The skills found to be important for a professional poker player include a mindset for success, commitment, patience, self-control and an aptitude for the game. Compared to recreational players, professionals appeared to spend considerably more time playing poker and were less likely to take risks or gamble under the influence of drugs or alcohol. Additionally, professional players' behavior was found to be more rational and cautious, while recreational players appeared to have a greater tendency to engage in less rational and less disciplined behavior. In short, professional players appear to be more rational, logical and disciplined in their behavior, whereas recreational players are more impulsive risk-takers and their behavior is not always logical (McCormack and Griffiths 2012). It appears that the inherent characteristics of professional and recreational gamers are clearly distinct, and their attitudes towards playing online poker are very different.

\section{Identification and refinement of choice features}

Although we focus on the differences between the two user groups (extrinsically-motivated and intrinsically-motivated gamers), we wanted to carefully design the empirical study so that the research instrument (features and their levels) reflects the actual decision-making process. Surprisingly, we found no available academic studies addressing the choice problem related to digital platforms; therefore, our approach to building the research instrument was exploratory in nature. Thus, we proceeded in three steps: first, we developed an initial set of features that potentially impact the consumer choice by reviewing the relevant literature on technology use (e.g. Nielsen 1993 and variants of TAM) and platform network effects (e.g. Parker et al. 2016). Second, we conducted expert interviews to operationalize and further validate the initial set of features to the context of online poker. Third, we made an empirical study by collecting data through a web-based survey using conjoint analysis. These steps allowed us to iteratively identify six features: 1) Usability, 2) Enjoyment, 3) Functionalities, 4) Poker network, 5) Loyalty program, and 6) Reputation, and empirically evaluate their respective impact on consumer choice calculus. Figure 2 illustrates our research process.

After having identified an initial set of criteria from earlier literature on technology assimilation and platform network effects, to operationalize the features in the context of online poker and to further validate the features found in the literature, we conducted four interviews with online poker players. The purpose of the interviews was to confirm that the criteria found was 

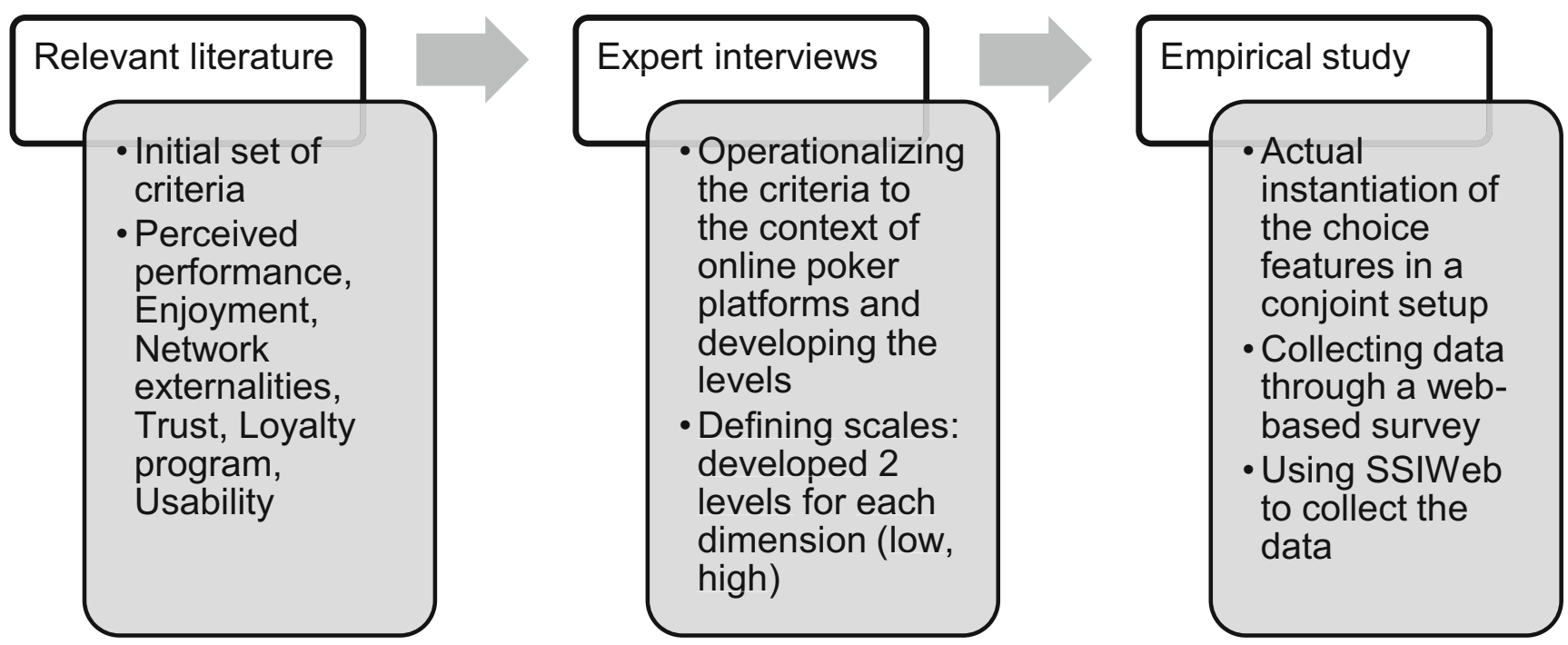

Fig. 2 Research process

relevant in the online poker context and discover any possible new features that might have gone unnoticed in the literature review. Data were gathered through interviews with online poker players who had different motivations for playing as well as different backgrounds. The interviews followed an outline that is provided in Appendix 2. A summary of the interviews is provided in the table below (Table 2), and the narratives of the expert interviews are provided in Appendix 3.

Next, we discuss each of the final six features and their origin, i.e. prior literature and expert interviews. We also take a stance whether each feature is linked primarily to extrinsic or intrinsic motivations (see summary of features in Table 3).

\section{Usability}

Literature The majority of past literature on technology assimilation has identified usability and ease of use as constructs that drive information technology use (Davis 1989; Gefen et al.
2003; Nielsen 1993). Although ease of use is often employed in existing studies as an antecedent of both perceived usefulness and perceived enjoyment (van der Heijden 2004), recently, perceived ease of use has been identified as a critical element to ensure flow in the specific case of mobile games (Merikivi et al. 2017). Thus, in our study, we link system usability primarily to intrinsic motivations. Concerning the operationalization of usability, ease of learning, ease of remembering, and low chance of committing errors during system use have been considered key components of system usability (Nielsen 1993).

Expert interviews All interviewees mentioned the usability of a poker site as a particularly important feature. It appears that all of the interviewees preferred a poker site with ease to use functions and a clear and simple graphical interface. The interviewees indicated that essential information regarding players, pots, chips, et cetera, should be clearly presented. In addition, the poker site should be reliable in the sense that it will not easily crash.

Table 2 Summary of expert interviews

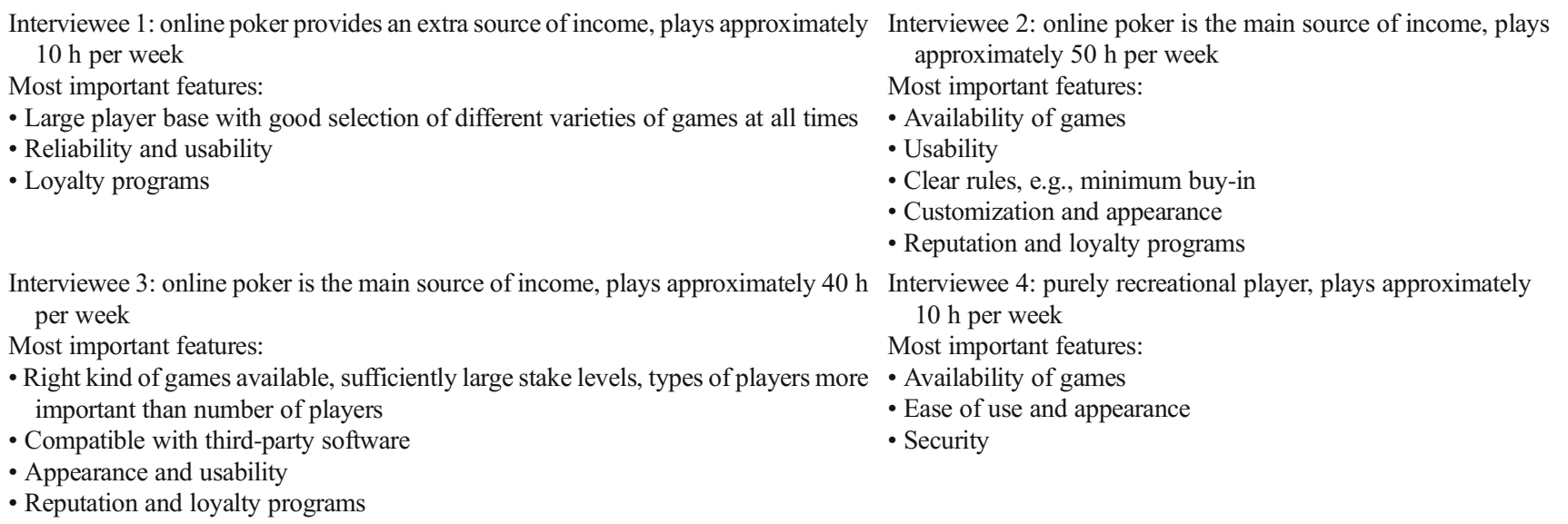


Table 3 Final set of features mapped against the main motivation type

\begin{tabular}{lll}
\hline Feature & Description & Extrinsic vs. intrinsic motivation \\
\hline Usability & Ease of using the online poker site & Primarily intrinsic \\
Enjoyment & Level of enjoyment factors such as graphics, sound and animation & Primarily intrinsic \\
Functionalities & Number of useful functionalities & Primarily extrinsic \\
Poker network & Size of the online poker site and number of suitable tables available & Primarily extrinsic \\
Loyalty program & Nature of the loyalty program & Primarily extrinsic \\
Reputation & Level of the reputation of the online poker site & Primarily extrinsic \\
\hline
\end{tabular}

Furthermore, extravagant sound effects and animations were considered to be more annoying than pleasant, and they were perceived to hinder the usability and reliability of the poker site. In short, the poker site should be easy to use, have a simple interface and should not crash easily.

Final feature The original attribute of perceived usability was labeled as "Usability" and operationalized as ease of using the online poker site.

\section{Enjoyment}

Literature Perceived enjoyment (van der Heijden 2004) is the extent to which a user experiences enjoyment while using the system, regardless of any performance improvements the system may provide. Hence, it focuses on measuring only intrinsic motivation to use or not to use a certain system. Furthermore, in the context of online gaming, enjoyment is found to play a significant role in predicting player satisfaction (Wu 2014).

Expert interviews As in the case of usability, enjoyment was mentioned by all interviewees as an especially important feature. Pleasant sounds, graphics, and animations were cited as enjoyment features associated with online poker sites; interviewees were annoyed with software that had poor sounds, graphics, and animations, and preferred a site that had pleasing graphical interface, sounds and animations.

Final feature The original attribute of perceived enjoyment was labeled as "Enjoyment" and operationalized in terms of enjoyment factors such as graphics (Wu et al. 2008), sounds and animation.

\section{Functionalities}

Literature Perceived usefulness is defined as the degree to which a person believes that using an information system would enhance his job or task performance (Davis 1989). It is typically the main extrinsic motivator identified in empirical studies on dualpurposed information systems (Wu and Lu 2013).
Expert interviews Interviewees claimed that certain features, such as bet-a-pot buttons, enhanced and improved the usefulness of the online poker site, thus allowing primarily extrinsically-motivated gamers to generate more profits. According to the interviewees, perceived usefulness of a poker site was considered to be improved by features such as compatibility with third-party analysis software, hand history, and similar features.

Final feature The original attribute of perceived usefulness was labeled as "Functionalities" and operationalized as the number and quality of functionalities.

\section{Poker network}

Literature Network externalities theory is concerned with the impact of the size of a network on the perceived value of the network by its user and acts as a foundation for the modern day understanding of network externalities. This theory was first crafted in 1980s and has since been refined by various authors (Farrell and Saloner 1985; Katz and Shapiro 1985, 1986). Essentially, online poker sites provide a platform that connects poker players throughout the world and allows them to play against one another. Thus, it is apparent that network externalities are present and are likely to play an important role in the factors affecting the choice behavior of online poker players. In the online poker context, the size of the network is perceived to be one of the most important features for creating value for players (Sieroty 2011). Furthermore, it has been discovered that achieving a critical mass of players is essential for the survival of the network. Since poker players want to be able to play at any time of the day and the system must be able to provide games at all times, a network must have critical mass.

Expert interviews When asked about the most important feature of an online poker site, all interviewees mentioned the availability of the games they like to play. In practice, availability roughly translates to the number of players who are part of the poker site network. For those players to whom playing poker constitutes an important source of income, the 
importance of the size of the network and types of games appears to be of paramount importance. Thus, it appears to be justifiable to conclude that network size appears to be a significant factor for extrinsically-motivated gamers when they consider which online poker site to use.

Final feature The original attribute of network externalities was labeled as "Poker network" and operationalized as the size of the poker network.

\section{Loyalty program}

Literature In the context of electronic commerce, loyalty incentives have been found to have an impact on consumer behavior and choice provided that the system is useful (Bhattacherjee 2001). Members of loyalty programs are generally less sensitive to losses in the dimensions of overall quality rating and billing aspects when comparing the company with competitors (Bolton et al. 2000). Thus, based on earlier literature on loyalty incentives, it appears to be safe to assume that in the online poker context, loyalty programs potentially have an impact on the choice behavior of poker players.

Expert interviews Poker sites award points for players based on how much they play. These points can be exchanged to different rewards, such as t-shirts and motor cycles. Thus, they work much in the same way as an airline or hotel loyalty program. Sometimes, a loyalty program is substantiated through "rake back" which is a promotional scheme that sites use to attract players to their site. In essence, it means that the poker site will return a certain percentage of the paid rake back to the gamer (see Appendix 1 for details, e.g., on rake). In expert interviews, availability of a loyalty program was the factor that divided the opinions of the interviewees the most. Based on the interviews, it appears that the availability of a loyalty program is an important factor for extrinsicallymotivated players who play medium stakes games. Conversely, intrinsically-motivated players tend to consider a loyalty program to be a somewhat less significant feature.

Final feature The original attribute of loyalty incentives was labeled as "Loyalty program" and operationalized as the level of comprehensiveness of the loyalty program.

\section{Reputation}

Literature Trust is a significant factor related to transactions that occur online (Eastlick et al. 2006; Hoffman et al. 1999; Siau et al. 2003). Trust elements have also been incorporated in theoretical models explaining information technology use. A study conducted by Gefen et al. (2003) found that for online transactions, trust was as important as perceived usefulness and ease of use. A recent study focused on online trust indicated that in addition to other factors, reputation is a significant factor that has an impact on trust and ultimately on whether a transaction occurs or not (Salo and Karjaluoto 2007).

Expert interviews Internet security and the reliability of poker sites were also found to be significant factors influencing the decisions of the interviewees. However, all interviewees claimed that the reputation of a poker site was the only real way to evaluate the reliability of an online poker site. Therefore, reputation in terms of the security and trustworthiness of a poker site can be considered to have a significant influence on the decision to accept or reject a certain online poker site.

Final feature The original attribute of trust was labeled as "Reputation" and operationalized as reputation of the online platform.

The following table (Table 3) summarizes the features and maps them against the main motivation type (extrinsic or intrinsic).

\section{Empirical study}

\section{Choice-based conjoint analysis}

As discussed earlier, the aim of the empirical study was to explore whether differences exist in how extrinsicallymotivated and intrinsically-motivated gamers choose a platform for online poker. Generally, research related to technology acceptance utilizes Likert scale style surveys to study the perceived importance of different constructs (Chismar and WileyPatton 2002; Hsu and Lin 2008; Lee et al. 2003). Compared to conjoint analysis, Likert scale value measurements have at least three shortcomings. First, Likert scales measure only one feature at a time and do not force the respondent to consider tradeoffs. Second, in Likert scales, the range is not normally fixed, which means that one can be asked about the importance of, for example, usability, but typically, the scale does not specify the nature of the worst or best levels of usability. In conjoint analysis, the range of the feature is fixed by assigning concrete feature levels. Third, conjoint analysis facilitates the assessment of response consistency. In conjoint analysis, the root likelihood (RLH) measures the fit of the utility function estimated with the observed choices. Respondents with low fit can be omitted, as the low fit normally occurs because of neglect and a lack of attention when responding to the survey (provided that the survey design is appropriate). This kind of tool is not readily available for traditional surveys. In addition, holdout questions can be used to measure the predictive capacity of the utility function to be estimated. If the simple additive model most often used is insufficient, even interaction terms can be 
included to improve the fit. For further discussion of the use of conjoint analysis in preference estimation and comparison to other methods, we refer the reader to (Johnson et al. 2006; Phillips et al. 2002).

Conjoint analysis allows us to assess respondents' utility functions related to e.g., a product or service, with their relevant attributes (features) as arguments. The method has been used for decades in preference estimation (Green et al. 2001), mostly in marketing research; currently, it is also increasingly used in a number of other areas, including electronic markets (Derikx et al. 2016), multichannel commerce (Trenz 2015), health care, food studies and transportation (Teichert and Shehu 2010). ${ }^{3}$ Along with the estimation of the utility functions, often measured at the segment or individual level, the relative importance scores of the features can be assessed. Currently, the most popular conjoint analysis type is the choice-based conjoint analysis (CBC). For this analysis, the respondents evaluate profiles of products or services, which can be hypothetical, and the respondents indicate the most preferred one. These kinds of tasks simulate the actual decisions of the respondents. For more technical information on the use of $\mathrm{CBC}$ analysis, we refer the reader to Appendix 4.

\section{Choice of feature levels}

When applying conjoint analysis to a problem, the first step is to define the features and their levels (our instrument includes 6 features with 2 levels as discussed in detail above), the type of conjoint analysis (our instrument employs $\mathrm{CBC}$ ) and the form of the utility function (our instrument is additive and later assesses possible interactions). Then, one needs to define the specifics of the conjoint analysis tasks: how many choice tasks to present (our instrument included 12 random tasks and 2 fixed tasks shared by all the respondents), how many profiles to present within each task (our instrument presented 3), and whether to include "No, I would not choose any of these" (our instrument did not offer this option). In addition, the data collection method must be chosen (our instrument was web-based, as it was the most efficient way to reach the respondents).

The six features chosen to be included in the analysis were introduced in Table 2 above. Only two levels were defined for each feature (Table 3 ) for two reasons. First, the choice of only two levels aimed to lower the cognitive burden the respondents experienced and to assure that the level of difficulty of the choice tasks offered to the respondents remained

\footnotetext{
${ }^{3}$ ISI Web of Knowledge lists 2612 references to articles or proceeding papers (in December, 2015) with "conjoint analysis" in the title, abstract or keywords. Of these studies, 2269 (88\%) were published in the past decade; 332 were related to business (ISI categorization, marketing), 71 were related to computer science and IS (see e.g., (Giessmann and Stanoevska-Slabeva 2013; Hann et al. 2007; Keil and Tiwana 2006; Kersten and Noronha 1999)) and 158 were related to operations research management science. Thus, the method has recently expanded outside the marketing field.
}

moderate. Second, as our sample included non-professional gamers, the research instrument needed to be as simple as possible. In professional settings where the decision-makers are better-equipped for such choices (such as an IT manager making a purchase decision concerning an IT-based enterprise information platform), the use of more features and levels is feasible. Moreover, using two levels was considered adequate; recall that the comparison of the valuations of two groups is the focus of this study.

No best practices or guidelines exist for how to create optimal levels (Louviere et al. 2010). Therefore, careful consideration and testing the levels with three pilot respondents was required before the analysis was finalized. One level was presumed to indicate high preference, whereas the other level was assumed to indicate strictly lower preference. Table 4 introduces the features and levels adopted.

\section{Data collection and sample}

To create the questionnaire, we used SSI Web 7.0 (Sawtooth Software). The profiles were described verbally (Table 4), and the choice tasks were generated by the software's design generator with the option "balanced overlap" (Chrzan and Orme 2000). This option generates a fractional factorial question design. The randomized design has the advantage of reducing bias due to order and learning effects. In total, there were 300 different versions of the questionnaire. We refer the reader to Appendix 5 for a screenshot of the research instrument.

After the survey was created, it was piloted by three people familiar with online poker to ensure that the survey worked properly and was comprehensible to respondents. The survey began with questions related to the background of the respondent. In the background section, demographic information, such as age, gender, profession, and experience with online poker, was collected. The respondents were also asked to identify the networks for which they currently had accounts.

Respondents for this research were contacted using Pokerisivut.com, the largest poker website in Finland. At the time of data collection, the website reported having more than 37,000 registered members (Wikipedia.fi). The website includes news, blogs, and discussion forums related to poker and online poker. In addition, the website operates as an affiliate site for most online poker rooms by providing different promotions to these rooms. The invitation to participate in the survey was presented in a new discussion thread at Pokerisivut.com, where the purpose and background of the study was briefly explained, and a link to the survey was provided. A news article about the survey and the invitation were published on the front page of Pokerisivut.com by the administrators of the website. By the time we downloaded the data, the thread had been exposed to 1539 gamers. The number of respondents who successfully completed the survey was 332 . Thus, the response rate for the survey is 21 . 
Table 4 The final features and levels in the conjoint analysis

\begin{tabular}{lll}
\hline Feature & Level 1 & Level 2 \\
\hline Usability & Poker site is easy to use & Poker site is difficult to use \\
Enjoyment & Graphics, sounds, and animations are enjoyable & Graphics, sounds, and animations are plain \\
Functionalities & Poker site offers a comprehensive set of functionalities & Poker site offers only basic functionalities \\
Poker network & Large number of players & Limited number of players \\
Loyalty program & Comprehensive loyalty program & Limited loyalty program \\
Reputation & Poker site has a proven reputation & Poker site has no established reputation record
\end{tabular}

$6 \%$. The following table (Table 5) provides the background information of the respondents (whole sample, extrinsicallymotivated and intrinsically-motivated players). Next, we proceed to explain how the demarcation between extrinsicallymotivated and intrinsically-motivated players was done.

\section{Treatment of extrinsically-motivated vs. intrinsically-motivated gamers}

After the aforementioned background questions, using a twostep procedure, the respondent was asked to indicate whether he/she plays professionally or recreationally. First, the respondent was asked whether he/she played professionally or for fun. This step yielded 80 respondents indicating professional play and 18 respondents playing for enjoyment. Second, the remaining respondents were asked to indicate whether they played online poker primarily to generate income or primarily for fun. This step produced 142 gamers primarily seeking to generate income from online poker and 92 respondents indicating that they play online poker primarily for fun. The answers to these questions indicated whether the respondent was treated as an extrinsically-motivated or intrinsically-motivated gamer in our empirical study (see Fig. 3).

Table 5 Demographic information of the respondents

\begin{tabular}{|c|c|c|c|c|c|c|}
\hline & \multicolumn{2}{|l|}{ Total sample } & \multicolumn{2}{|c|}{ Extrinsically-motivated } & \multicolumn{2}{|c|}{ Intrinsically-motivated } \\
\hline & $\begin{array}{l}\text { Number of } \\
\text { respondents }\end{array}$ & $\%$ & $\begin{array}{l}\text { Number of } \\
\text { respondents }\end{array}$ & $\%$ & $\begin{array}{l}\text { Number of } \\
\text { respondents }\end{array}$ & $\%$ \\
\hline \multicolumn{7}{|l|}{ Gender } \\
\hline Male & 330 & $99 \%$ & 220 & $99 \%$ & 110 & $100 \%$ \\
\hline Female & 2 & $1 \%$ & 2 & $1 \%$ & 0 & $0 \%$ \\
\hline \multicolumn{7}{|l|}{ Age } \\
\hline $18-25$ & 157 & $48 \%$ & 116 & $52 \%$ & 41 & $37 \%$ \\
\hline $26-45$ & 160 & $48 \%$ & 100 & $45 \%$ & 60 & $55 \%$ \\
\hline $46-65$ & 14 & $4 \%$ & 5 & $2 \%$ & 9 & $8 \%$ \\
\hline $66-100$ & 1 & $0 \%$ & 1 & $1 \%$ & 0 & $0 \%$ \\
\hline \multicolumn{7}{|l|}{ Occupation } \\
\hline Employed & 126 & $38 \%$ & 60 & $27 \%$ & 66 & $60 \%$ \\
\hline Student & 108 & $33 \%$ & 79 & $36 \%$ & 29 & $27 \%$ \\
\hline Entrepreneur or self-employed & 47 & $14 \%$ & 41 & $19 \%$ & 6 & $5 \%$ \\
\hline Retired & 2 & $1 \%$ & 1 & $0 \%$ & 1 & $1 \%$ \\
\hline Unemployed & 33 & $10 \%$ & 25 & $11 \%$ & 8 & $7 \%$ \\
\hline Other & 16 & $5 \%$ & 16 & $7 \%$ & 0 & $0 \%$ \\
\hline \multicolumn{7}{|l|}{ Experience with online poker } \\
\hline Less than 12 months & 5 & $2 \%$ & 1 & $0 \%$ & 4 & $4 \%$ \\
\hline $1-2$ years & 23 & $7 \%$ & 13 & $6 \%$ & 10 & $9 \%$ \\
\hline $3-4$ years & 95 & $29 \%$ & 63 & $28 \%$ & 32 & $29 \%$ \\
\hline $5-6$ years & 161 & $48 \%$ & 112 & $51 \%$ & 49 & $45 \%$ \\
\hline 7 years or more & 48 & $14 \%$ & 33 & $15 \%$ & 15 & $13 \%$ \\
\hline Total & 332 & $100 \%$ & 222 & $100 \%$ & 110 & $100 \%$ \\
\hline
\end{tabular}




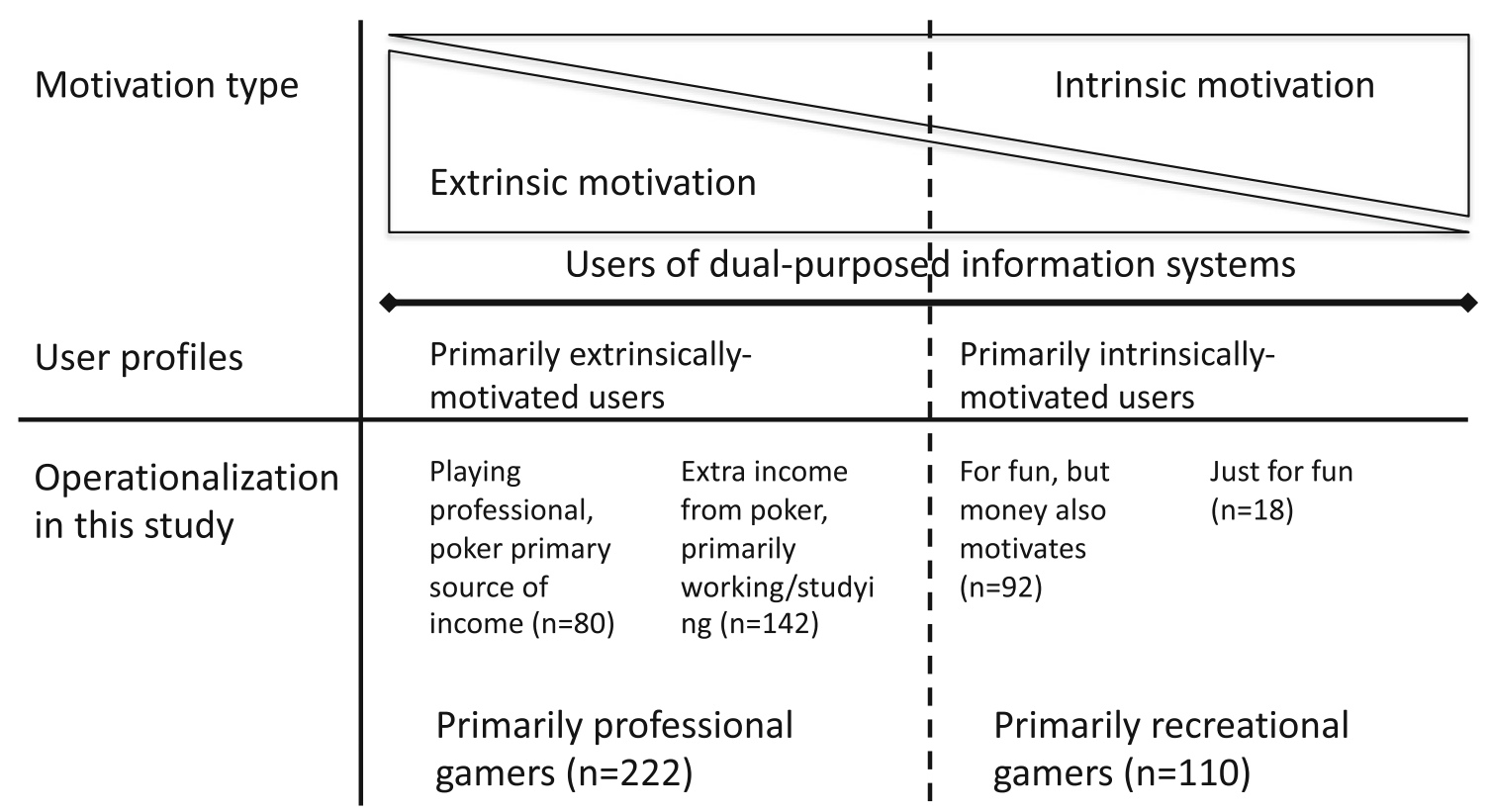

Fig. 3 Operationalization of extrinsically-motivated and intrinsically-motivated gamers

We acknowledge that whether a player considers himself/ herself extrinsically or intrinsically motivated is similar to a line drawn in the water. It is natural that the two roles are mixed to some extent. Hence, the underlying variable describing the player's mindset is inherently a fuzzy continuous variable. However, a player will usually be able to indicate which role is more dominant. Therefore, we consider that asking the player to indicate extrinsic or intrinsic motivation is sensible when the choice is interpreted as a description of the dominant role rather than being mutually exclusive options. Alternative methods to distinguish between extrinsically-motivated and intrinsically-motivated gamers do exist; participants could have been asked about their motivations using a questionnaire consisting of extrinsic and intrinsic motivation items with associated Likert scales. This approach would have resulted in a researcher-defined cutoff point between extrinsicallymotivated and intrinsically-motivated gamers based on the values of the items. Instead, we decided to directly ask the respondent to indicate the dominant role in which he/she plays on the gaming site. We consider this approach to be well justified for the difficult task of distinguishing between those users who primarily play for income purposes and those who primarily play for fun.

\section{Findings}

Before analyzing the differences between extrinsicallymotivated and intrinsically-motivated users, we used the aggregate level model and found that all features influence the choice of an online poker platform, i.e., all the part-worths have a t-ratio of 3.9 in absolute value as the minimum, indicating that they are non-zero $(n=332)$ (Table 6). Although our objective was not to probe the ranking of the features, we found that reputation was the most important feature for the respondents overall, followed by the poker network, loyalty program, enjoyment, usability and functionalities.

Based on the conjoint task responses, the part-worths were estimated for the two different player types to analyze the importance of the different features for the two groups and to test whether differences exist in the valuations across the groups. The importance scores are presented in Table 7. We note that the ranking of the importance of the features is almost equal across the groups. Testing the equality of importance scores resulted in only one significant difference: the importance score of the loyalty program is greater for extrinsically-motivated players, with a confidence level of $99.7 \%$. Note that here, the estimation method was a hierarchical Bayes method with covariates, where the statistical inference differs from that of classical statistical theory (Gelman et al. 2013). The next most prominent difference was that enjoyment was more important for the intrinsically-motivated players, with a confidence level of $76 \%$, meaning that the confidence that the opposite is true is $24 \%$ (as indicated in Table 7). The additive utility model was applied in the calculations. $^{4}$

The confidence level $a$ reported in the rightmost column is the Bayesian confidence that the importance for the extrinsically-motivated user is greater than that for the

\footnotetext{
${ }^{4}$ The significance of interactions was tested by adding them to the model one at a time, and none were significant at a risk level of $1 \%$.
} 
Table 6 Part-worth utilities of the aggregate model

\begin{tabular}{|c|c|c|c|}
\hline Feature & Level & Part-worth utility & t-ratio \\
\hline \multicolumn{4}{|c|}{ Reputation } \\
\hline & Poker site has a proven reputation & 113.53641 & 35.44669 \\
\hline & $\begin{array}{l}\text { Poker site has no established } \\
\text { reputation record }\end{array}$ & -113.53641 & -35.4467 \\
\hline \multicolumn{4}{|c|}{ Poker network } \\
\hline & Large number of players & 75.41994 & 26.12372 \\
\hline & Limited number of players & -75.41994 & -26.1237 \\
\hline \multicolumn{4}{|c|}{ Loyalty program } \\
\hline & Comprehensive loyalty program & 59.75309 & 21.80816 \\
\hline & Limited loyalty program & -59.75309 & -21.8082 \\
\hline \multicolumn{4}{|c|}{ Enjoyment } \\
\hline & $\begin{array}{l}\text { Graphics, sounds, and animations } \\
\text { are enjoyable }\end{array}$ & 20.97837 & 8.23203 \\
\hline & $\begin{array}{l}\text { Graphics, sounds, and animations } \\
\text { are plain }\end{array}$ & -20.97837 & -8.23203 \\
\hline \multicolumn{4}{|c|}{ Usability } \\
\hline & Poker site is easy to use & 20.67606 & 8.23993 \\
\hline & Poker site is difficult to use & -20.67606 & -8.23993 \\
\hline \multicolumn{4}{|c|}{ Functionalities } \\
\hline & $\begin{array}{l}\text { Poker site offers a comprehensive } \\
\text { set of functionalities }\end{array}$ & 9.63613 & 3.90292 \\
\hline & $\begin{array}{l}\text { Poker site offers only basic } \\
\text { functionalities }\end{array}$ & -9.63613 & -3.90292 \\
\hline
\end{tabular}

intrinsically-motivated user and the confidence for the opposite is $100-a$.

As for reliability when estimating the individual utility functions using hierarchical Bayes estimation, the aggregate fit measure exceeded the fit for a respondent making choices randomly by $118 \%$. Thus, it appears that based on the responses, it is truly possible to estimate utility functions that predict the respondents' choices. Next, we present our alternative interpretations of the results, followed by our discussion of the theoretical and managerial implications of our study.

\section{Discussion}

New models for understanding and explaining IS use have been introduced to include users who are extrinsically or intrinsically motivated. In this study, we assumed that an online poker site would represent an appropriate IT-based dualpurposed information system to study the differences among users with different motives, since people who play for fun and people who play to make money use the same sites simultaneously. However, our results were somewhat unexpected, since only one significant difference in feature importance scores was discovered across the player types: the importance score for loyalty programs was statistically higher for extrinsically-motivated gamers. The most striking finding in our empirical study was that even the features that one would expect to be directly linked to extrinsic motivation such as functionalities, size of the poker network, and platform reputation were weighed evenly by both types of users. Similarly, features that would be expected to have more importance to hedonic usage, such as enjoyment and usability, were equally
Table 7 Relative importance score percentages across the user groups

\begin{tabular}{llll}
\hline Feature & $\begin{array}{l}\text { Extrinsically-motivated } \\
\text { user, importance score }\end{array}$ & $\begin{array}{l}\text { Intrinsically-motivated } \\
\text { user, importance score }\end{array}$ & $\begin{array}{l}\text { Confidence that } \\
\text { the extrinsically-motivated } \\
\text { user sets higher importance }\end{array}$ \\
\hline Reputation & 38.7 & 40.6 & NS (56.1) \\
Poker network & 24.4 & 26.4 & NS (43.9) \\
Loyalty program & 21.4 & 15.7 & $* * *(99.7)$ \\
Enjoyment & 6.1 & 7.6 & NS (24.0) \\
Usability & 6.4 & 6.9 & NS (45.9) \\
Functionalities & 2.9 & 2.8 & NS (59.8)
\end{tabular}


important to both user groups. Next, we discuss some possible reasons and alternative interpretations for these results to initiate a discussion and present possible avenues for future research.

Interpretation \#1: Currently, many people do not make a clear distinction between work time and leisure time instead these periods of time are often mixed or intertwined. In the case of online poker, it may be possible that despite playing for utilitarian reasons, the players concurrently experience hedonic benefits. This outcome is similar to, for example, top athletes who enjoy what they do although they earn a considerable amount of money while doing it. Initially, it would sound intuitively obvious that people are often in different consumer states depending, for example, on the time, place, and space. Further, this finding makes us assume that our utility function would be different for these different states as well. However, our study did not confirm such assumptions, but rather corroborates the analyses of earlier literature on blurring in the leisure-work nexus (Adler and Adler 1999). Overall, this interpretation of our findings calls for more in-depth studies to better understand when, how, and why our preferences change towards a given IT service or services in general. Here, as boundary condition, we must bear in mind that in our empirical setting we studied dual-purposed information systems which are probably more prone to this kind of blurring between work time and leisure time. Purely utilitarian (e.g. ERP systems) or hedonic (e.g. on-demand TV) systems might yield more demarcated feature preferences.

Interpretation \#2: It is possible that our participants do not consciously choose the site. Even if all respondents reported that were familiar with a number of poker sites and that they have at least tried to use them, it remains possible that they actively use only one of the sites. It is possible that the players regularly use one of the sites regardless of whether they play for fun or to make money. Some of them may have already developed a habit of connecting to their favorite poker site. If sites are very similar, it is not necessary to use different sites for different purposes. The fact that the only difference we found between the player types was the greater significance of the loyalty program for the extrinsically-motivated players may further support this claim.

Interpretation \#3: Our results may indicate that all poker sites share roughly similar features and functionalities or at least the players perceive them to be equally attractive. If so, the site does not play a key role but the games or tables provided by a site may play a key role. The size of the player network was the second most important feature for both player types, which indicates that this speculation might be true and means that, in general, the user interface has lost its importance while the services have matured to offer satisfying experiences independent of the site. This interpretation of our results corroborates the thesis of Carr (2003) in claiming that IT services might be becoming commodities and thus not differentiable from each other.

\section{Theoretical implications}

We note two main theoretical contributions. First, previous literature addressing the motivational aspects for using utilitarian, hedonic, and dual-purposed IS has found that extrinsic motivations drive the use of utilitarian systems and that intrinsic motivations drive the use of hedonic systems (Babin et al. 1994; Li et al. 2015; Wu and Lu 2013). We find that when selecting the dual-purposed platform for online gaming, both groups of gamers (extrinsically-motivated and intrinsicallymotivated) appear to weigh the platform features equally. Thus, our findings contradict the claim that the importance of utilitarian or hedonic factors is perceived differently by different groups of users (Gu et al. 2010). Interestingly, in their study on utilitarian, hedonic, and dual-purposed IS, Wu and Lu (2013) made a similar contradictory finding: "in the context of dual-purposed information systems, extrinsic and intrinsic motivators evenly share predictive power; they nearly "average out"" (Wu and Lu 2013, p. 168). Our study supports this finding; in our case, the selection of the online gaming platform appears to be insulated from the motivation to play. We claim that the interrelatedness and intertwining nature of extrinsic and intrinsic motivations (Verhagen et al. 2012) might be accentuated in the context of dual-purposed IS compared to strictly utilitarian or hedonic systems.

Second, previous research on IS assimilation has identified distinct assimilation stages that include awareness, adoption, and deployment (Bala and Venkatesh 2007) and has called for more rigorous research on IS assimilation and its links to extrinsic and intrinsic motivations ( $\mathrm{Wu}$ and $\mathrm{Lu}$ 2013). We searched for studies that address the impacts of extrinsic and intrinsic motivations on system selection and surprisingly found a lack of studies on this topic. To date, very little research has probed the decision associated with selecting an IS or an IT-based platform and how different types of motivational factors impact the choice. Our study provides a first attempt to make theoretical claims on consumer choice calculus and customer preferences related to this selection problem. Rather than relying on self-reported Likert scale responses on factors that may affect any part of the assimilation stage, we decided to employ a somewhat uncommon method in conjoint analysis that requires the respondents to select a suitable platform profile and as a result make clear trade-offs between platform features. After studying the abovementioned stages of IS 
assimilation, we encourage researchers to acknowledge that system selection is an important dimension to consider when studying IS assimilation.

\section{Managerial implications}

What should managers working in the field consider when making decisions, particularly regarding product development, strategy and communications? Next, we provide guidelines for managers, first by analyzing the overall ranking of the features and second by noting the lack of differences between the user groups.

In the overall ranking of the features, reputation emerged as the most important feature for all players. For an online poker site, creating a strategy that aims to foster the reputation of the site and a strong brand image are likely to improve the overall competitive advantage of the site. Managers should focus on establishing effective communication practices between the service provider and customers, providing transparency regarding business operations, and ensuring a consistent trackrecord of seamless service without interruptions. Reputation probably correlates with platform size: as stated by one of the interviewees, large and well-known companies are preferred over small and less known ones.

The second most important feature overall was the network size of the poker site. Obviously, a primary objective for managers of online poker sites should be to attract as many players to the network as possible. The expert interviews indicated that the variety of games is an important issue. Therefore, we suggest that managers should consider not only the size of their online poker site network but also the heterogeneity of the players and games the site can offer.

The great importance given to the loyalty program presumably has the most important implications from a marketing perspective. It appears that a loyalty program is significantly more important to extrinsically-motivated players than to intrinsically-motivated players. Therefore, managers responsible for marketing and promotion should consider this issue as they make marketing investments and decisions concerning segmenting their customers. Extrinsically-motivated players are likely to be more interested in loyalty programs, whereas intrinsically-motivated players may not perceive these programs as important.

Our empirical study showed very few differences between extrinsically-motivated and intrinsically-motivated players; the only statistically significant difference was the high importance of the loyalty programs for extrinsically-motivated players. In terms of product development, it appears that both player types deem attributes related to the actual characteristics of the software as less important than, for instance, reputation. Because discrete choice experiments tend to provide results that focus on only two attributes, it is essential not to ignore the importance of having well-functioning, easy-to-use software. However, many survey respondents reported that they are willing to learn to use even more difficult software if the games on the platform are perceived as good. As indicated by their comments, many respondents also appreciate the ability to modify the appearance of the software themselves. Therefore, it appears that if the service provider is unwilling to invest large sums in developing the software to be as easy to use and as enjoyable as possible, it should, at a minimum, keep the system open to allow modification by the users. However, one should bear in mind the fairly obvious discovery that compared to other players, beginners place a significant emphasis on the ease of use of poker sites.

In general, it appears that the software currently provided by poker sites includes all of the useful functions and is easy to use and enjoyable. This fact could explain why reputation and network size were considered such significant attributes. However, as the industry is still fairly young, it is more than likely that there is room for improvement, and many innovations may be added in the future. Therefore, we recommend that managers actively seek ways to improve the customer experience on their online poker sites.

\section{Limitations and avenues for further research}

Our study is not without limitations. First, we consider one specific context of dual-purposed IS: online poker. Online poker is subject to significant network effects and possibly addictive behavior for both extrinsically-motivated and intrinsically-motivated players, which may have distorted our findings. Further research should study other contexts subject to varying degrees of network effects and proneness to addictive behavior. Second, our sample includes responses that were provided at one point in time and from only one geographical area: Finland. Future research should assess whether the features are dynamic and change over time. Similarly, there might be cultural differences in how extrinsically-motivated and intrinsically-motivated players make their choices. Our sample was heavily skewed towards male gamers with very few responses from female gamers. Although online poker gamers are predominantly male, future research should ensure a healthier sample balance between male and female gamers. Furthermore, readers of our study should bear in mind that the survey was conducted in Finnish and that nuances in the translation associated with the features and feature levels might impact the results. Third, we relied on self-reporting of the player state (a four-scale classification of extrinsicallymotivated and intrinsically-motivated players), and in the empirical study, we treated the player state as a dichotomous concept. Further research should critically review these assumptions. Fourth, although our purpose was to examine the potential differences between the two user groups and not to develop a ranking of the most important 
features, we wanted to ensure that the features used in the empirical study reflect the actual decision-making situation. To establish the set of features, we used a limited number of interviews to operationalize, validate, and develop the scale for each feature. Future research could attempt to determine the most important features of platform selection. Fifth, a common limitation in using conjoint analysis is related to developing the feature levels. We did not use a middle level anchoring point; instead, we used two levels (high-low). While we note that the selection of the levels would be more relevant when studying the overall ranking of the features, the selection of the levels may have had an impact on the findings concerning the differences of the two user groups.

\section{Conclusion}

This study explored whether differences exist between extrinsically-motivated and intrinsically-motivated users in terms of their selection of online platforms. Based on previous literature on IS assimilation and by conducting expert interviews to improve validity, we developed our research model, which includes six features of online gaming platforms that might influence users' decisions related to selecting platforms. The features were usability, enjoyment, functionalities, poker network, loyalty program, and reputation. When comparing the preferences of the two groups of gamers, of the six features, only the importance score of the loyalty program was significantly different between the two user groups; this feature was more important for extrinsically-motivated gamers. One would have expected to see significant differences in the other features as well. We interpret this surprising finding as providing support to the claim that extrinsic and intrinsic motivations have shared predictive power for using dualpurposed IS and to the overall intertwining nature of hedonic and utilitarian values. In the sections above, we outlined several alternative interpretations for our findings, which we hope to open new avenues for studies on dual-purposed IS.

\section{Appendix 1}

Table 8 Fact sheet on poker and alternative ways of playing poker (Vilen 2013)

Definition

Poker is: "A card game... played by two or more people who bet on the value of the hands dealt to them, one of whom wins the pool either by having the highest scoring combination of cards at the showdown, or by forcing all opponents to concede without a showing of the hand, sometimes by means of a bluff" (The Oxford English dictionary). The most commonly known variants of poker are the classic five-card draw, Texas Hold'em, and Omaha. In all poker games, won or lost money transfers from the loser to the winner (Pokernews.com).

Alternative ways of playing When the game occurs at a casino, the party responsible for facilitating the game (i.e., a casino or a poker room) takes a poker small percentage out of every pot, called 'rake', or charges an hourly fee for playing (Wikipedia). Stake levels vary significantly, from low to practically infinite, based on the wealth of the players. Generally, poker stake levels are divided into four groups: micro stakes, small stakes, medium stakes, and high stakes. Micro stakes are not generally available at traditional casinos because they are too small to generate sufficient income for the casino. Small stakes games are usually the smallest games available at brick and mortar casinos, and most casinos have no upper limit for the stake levels.

Poker is most commonly played at casinos, in special poker rooms, and at gamers' own homes. The problem with casinos and poker rooms is that for many people, they might be hard to reach, as casinos are generally in geographically distinct locations (Wood et al. 2007). For instance, in Finland, there is only one casino that is allowed to offer the full range of casino games. Some people may also feel that extra effort is required to get into a casino, as some places may require customers to dress according to certain guidelines, register as a customer or pay for membership. The first visit to a casino may seem particularly intimidating for many people. In addition, the stake levels available at casinos may also feel slightly high for a first timer who is learning how to play poker.

It seems that numerous small obstacles exist, which may have keep potential players from going to a casino to try poker. Thus, it appears fairly logical that poker in its traditional form has not become as popular as it could have become due to these impeding factors, until the introduction of online poker.

Online poker

Online poker rooms function in the same way as traditional land-based poker rooms or casinos except everything occurs online. To be able to play, one must create an account, for which an email address is needed. Depositing money is not usually a requirement, as practically all known online poker rooms provide an opportunity to start playing with play money. Thus, investing money in the beginning is not necessary, which has probably been a significant factor for lowering the entry barriers into the world of poker. As people can access and practice poker from the safety of their own home without the fear of losing money, it is easy to see why an increasing number of people have been eager to try it, have gotten excited and then ultimately deposited real money into their account. Furthermore, unlike traditional brick 
Table 8 (continued)

and mortar casinos, micro stakes poker games are available in online poker rooms. Thus, it is easy to start playing with real money, as one can start with very small stakes and proceed to larger games as skills and willingness to take risks increase.

The first form of online poker emerged in the early 1990s, when online poker was played as a text only version over Internet Relay Chat (IRC). As the game was lacking a graphic user interface and real money. Mainly computer enthusiasts played it. In early 1998, Planet Poker was launched, which was the first real online poker room that intended to provide the land-based poker experience online. In late 1999, Paradise Poker was introduced, which provided a sleeker user interface with significantly faster software. In 2001, PartyPoker.com launched its poker room and a guaranteed one-million-dollar tournament (Flopturnriver.com). In 2004, Full Tilt Poker entered the market with a poker pro-led strategy and an emphasis on high quality software. In 2006, the Unlawful Internet Gambling Enforcement Act forced all public companies to pull out of the US market. As a result, only PokerStars and Full Tilt were left serving American online poker players, as they were both privately held (Pokerplayer.co.uk). In 2011, the remaining major operators were essentially wiped out of the market, as they were all charged by the FBI with money laundering and using defrauded banks to bypass the abovementioned gambling act (Sieroty 2011). However, lately, PokerStars and Absolute Poker have been able to return to the market.

The exact number of poker networks or sites available is difficult to determine, as networks and poker sites tend to merge, disappear or appear rather quickly. However, pokerscout.com ranks known poker sites or networks according to their traffic. The listing claims that there are 68 existing poker sites (as of February 10, 2016). However, some of these poker sites appear to have no traffic at all, so they can be considered nonexistent. Only ten poker networks are truly global and appear to have traffic. When considering both global and local-only networks, the number of active networks increases to approximately forty.

\section{Appendix 2: Expert interview questions}

Each interview started by covering the background of the interviewee and identifying whether the interviewee was considered to be primarily extrinsically-motivated or intrinsically-motivated. The second part of the interviews consisted of questions related to online poker sites, their attributes and whether the interviewees preferred various attributes of the poker sites. The second part started with questions that allowed the interviewees to freely state any features they felt to be important. The questions became more specific towards the end of the interview to gain a more profound understanding about a number of essential issues important for this survey and to confirm the criteria found in the literature review. To clarify, the questions at the beginning of the interview were broader to allow any criteria to emerge that were not discovered during the literature review. All of the questions in the interview were open-ended. All interviews were recorded and transcribed.

\section{Background}

1. How long have you played online poker?

2. Is poker your main source of income?

3. How many hours, on average, do you spend playing poker per week?
4. At what stake level do you currently play? (Micro, small/ low, medium, or high)

5. Do you think you play to a) to earn money or b) just for fun?

6. A question based on the answer to the previous question

a. Do you occasionally also play just for fun?

b. Do you occasionally also play only to earn money?

\section{Poker software}

1. What do you consider to be the most important feature of when choosing a poker site?

2. What other features of a poker site do you consider to be important?

3. Do you use more than one poker software at the moment? Why?

4. What features make a poker site useful?

5. What features make a poker site pleasant to use?

6. Does the Internet security of a poker site influence your decision to use or not to use it? How do you recognize a secure/unsecure site?

7. Does the image or reputation of a poker site influence your decision to use it or not to use it?

8. Does the loyalty program/rakeback contract influence your decision to use or not to use a particular poker site? 


\section{Appendix 3}

Table 9 Narratives of the expert interviews

Interviewee 1: Juuso Hytönen

Hytönen is a 24-year-old Finnish business school student who has been playing online poker for six years. He says that online poker provides him an extra source of income, but he spends the majority of his time studying and claims that student aid is his main source of income. Hytönen estimates that he plays online poker approximately $10 \mathrm{~h}$ per week at the medium-stakes level. He states that he plays poker essentially to earn money, but he admits that he might sometimes play online poker only for fun.

Interviewee 2: Aaro Valkila

Valkila is a 24-year-old Finnish professional poker player who has been playing online poker for approximately two years. He has been playing professionally for a fairly short time. Poker winnings are his main source of income at the time of the interview, and he estimates that he spends approximately $50 \mathrm{~h}$ playing poker per week. Valkila plays medium stakes poker games. He says that he plays primarily Texas Hold'em to earn money, but he sometimes plays other poker games just for fun (e.g., Omaha). Thus, he is considered to be a professional player who may occasionally engage in recreational playing.

\section{Interviewee 3: Sami Kelopuro}

Kelopuro is a 24-year-old professional poker player who has been playing online poker for six years. Kelopuro lives in Finland and plays poker both online and offline but mainly online. Poker is the main source of income for Kelopuro, and he estimates that he spends approximately
For Hytönen, the most important features of an online poker site are that the site has a large player base and that there is a good selection of different varieties of poker games available at all times. Secondary features that are important to him include reliability and usability. He wants to use a poker site that runs smoothly and does not crash. In addition, he thinks that he is willing to play with a poker site that is slightly harder to use if the games available are very good.

Hytönen thinks that a pleasant poker site should have a simple interface, so that it is quick and easy to see what occurs at the tables, how much money each player has, et cetera. He also thinks that buttons that allow you to bet, for instance, $3 / 4$ pot make a poker site more pleasant to use, as they make playing more effortless. Such features also make the poker site more useful in his opinion, as it allows for quicker action and decision-making, which allows him to play more hands per hour and increase his expected profits.

Hytönen claims that it is difficult to determine whether a poker site is secure or not and that he mainly relies on the reputation of a poker site, which he evaluates for safety and trustworthiness. However, he thinks that the security of a poker site is an important factor; therefore, the reputation of a poker site greatly influences his decision to use or not to use it.

Finally, Hytönen thinks that loyalty programs are also a major factor influencing his decision-making. He says that if a poker site did not offer a rakeback contract, he would probably decide not to use it. He says that the amount he is able to receive through a rakeback is so significant that it would not be reasonable for him to play without such a contract.

The most important feature of a poker site for Valkila is that the site would always have the games that he likes to play available. In other words, he states that the availability of the right games, in essence, means that the player base of the poker site is large enough.

Almost equally important for Valkila is the usability of the poker site. Valkila explains that there are significant differences among poker sites in terms of their usability and that for him, the usability of a poker site is very important.

Valkila thinks that, in general, having rules such as a minimum buy-in for a table and enough time to think about each decision makes a poker site useful. Regarding the actual software, Valkila thinks that having bet sliders or buttons that allow you to bet, for instance, $1 / 2$ pot is a very useful feature. In addition, Valkila thinks that an automatic buy-in feature makes his playing more efficient. Furthermore, having good waiting lists for ring games improves the usefulness of a poker site, in Valkila's opinion.

Valkila states that the same features that make a poker site useful also influence the enjoyment of its use. However, he mentions that the ability to customize the graphics or appearance of the poker site makes the use of the site more pleasant. Generally, he thinks that a poker site that is pleasant to use has a nice interface in terms of its appearance.

Reputation is also an important factor determining whether Valkila chooses to use a particular poker site or not. According to him, reputation is the only way he can evaluate the security or reliability of a poker site. For this reason, he tends to prefer well-known poker sites that are used by his acquaintances and tries to avoid poker sites that may have a questionable reputation or no reputation at all.

Finally, Valkila claims that a loyalty program is an important factor for him, and he always considers the rakeback-percentage before deciding which poker site he is going to use. In general, he says that a loyalty program is a significant factor for him.

The single most important feature for Kelopuro is that he can find the right kind of games on the online poker site, which practically means that he is able to find games that have large enough stake levels that have some 'value' for him, meaning that he considers that he is capable of playing the game profitably. He claims that the size of a network does not 
Table 9 (continued)

$40 \mathrm{~h}$ per week playing online poker. Kelopuro plays high stakes poker games. According to Kelopuro, when he plays poker, his intention is to win money; therefore, he is considered to be purely professional and, thus, primarily extrinsically motivated.
Interviewee 4: Pasi Vilén

Vilén is a 45-year-old IT consultant from Finland. Vilén has been playing online poker for four years, and he considers himself to be a purely recreational player and plays only for fun. He estimates that he spends, on average, $10 \mathrm{~h}$ a week playing online poker. Vilén plays low and medium stakes poker games. unambiguously correlate with the availability of the right kind of games. According to Kelopuro, it is more important to have the right kind of players in the network than to have a vast number of players in the network. The reason Kelopuro has fairly specific demands for the right kind of players is probably the fact that the number of players in the world who play the level of stakes that he prefers is fairly limited. In addition, most players of these games are professionals and among the best in the world. Therefore, for the games to be profitable, it is essential to find the weakest among these players.

Another important feature of an online poker site important to Kelopuro is that the poker site is compatible with third-party poker tracking and analysis software (e.g., Hold'em manager, PokerTracker) and services (e.g., pokertableratings.com). In addition, Kelopuro considers the look and usability of the poker site to be important factors. He says that he becomes annoyed with software that has poor sounds, graphics, and animations and prefers a site that has a pleasing graphical interface, sounds and animations. In addition, he thinks that if the user can somehow modify a poker site's appearance, it makes the site more pleasant. To conclude, Kelopuro considers simple sites that are easy and effortless to use to also be pleasant to use. Too many or overly complicated animations, sound effects and other types of effects may cause too much confusion and make a site too slow to use.

Furthermore, Kelopuro notes that features that increase the usefulness of a poker site are important to him. In his opinion, features that increase the usefulness of a poker site include options such as a bet slider and buttons that allow you to automatically bet, for instance, $33 \%$ of the total pot and to review a past hand easily and quickly. In addition, he thinks that the filters in the poker site lobby that allow players to find the right games or tables are important and useful features, as they allow the player to quickly find and get into the best games available at any given moment. Kelopuro thinks that the reputation of a poker site is essentially the only way he can determine whether a poker site is secure and reliable. He thinks that security and reliability are important factors, but he also recognizes that online poker sites may have limited capabilities to prevent certain problems, such as someone accessing another player's computer, seeing the other player's cards and taking advantage of the situation. In practice, he thinks that a site's Internet security is based on news and rumors, but such things do influence his decision to use or not to use a certain poker site.

Finally, Kelopuro says that he always chooses the best available loyalty program for each poker network, as multiple skins are usually available for a poker network and all offer slightly different loyalty programs. Kelopuro claims that a loyalty program is not the only reason to use or not use a certain poker site as such, but once a decision has been made to use a specific poker network, he will choose the poker room on that network that offers the best loyalty program. The impact of a loyalty program per se is fairly small according to Kelopuro.

The most important feature of poker site for Vilén is the availability of the games he wants to play, which in practice means that the poker site is part of a network that has a large player base. Other significant features that Vilén considers important are that the software is easy to use, which means that you can easily find and join the games you want to play, and that the appearance of the software is neat.

In Vilén's opinion, useful features include options such as appropriate filters in the lobby that allow you to quickly find the right tables and that players are not given too much time to think about their decisions, which improves the flow of the game. In addition, he mentions that another useful feature of a poker site is the absence of excessive animations or graphics.

Vilén thinks that a poker site that is pleasant to use should have pleasing colors and essential buttons and functions are easy to use and quick to find. In addition, important information, such as the amount of money in the pot or the amount each player has in chips, should be clearly 
Table 9 (continued)

displayed. Generally, Vilén claims that a pleasant site is simple and easy to use.

Vilén says that the security of a poker site is an important factor for him, but it is difficult to determine whether a site is secure. He says that one can identify that payments are made using a secure connection, but all other perceptions related to the security and reliability of a poker site are based on the reputation of the site. For this reason, Vilén says that he tends to prefer sites that are run by well-known companies. Finally, he says that loyalty programs may have some impact on his decision when he is choosing a poker site but that rakeback programs have little importance for him is very little. 


\section{Appendix 4: Choice-based conjoint analysis}

In choice-based conjoint analysis (CBC), the total perceived utility $U$ is the sum of the total value $V$ and a random error term $\varepsilon$ present in the valuation of a product: $U=V+\varepsilon$. In practice, $V$ is quite frequently an additive function of the product features (sometimes with interaction terms). Each feature typically has between two and eight possible values that are referred to as levels. If there are $n$ features denoted by $a_{1}, a_{2}, \ldots, a_{n}$, then the total utility $U$ is.

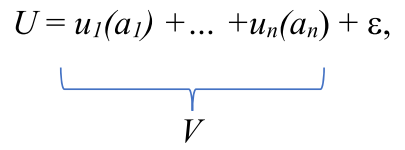

where $u_{i}$ is the utility function of an individual feature $i, i=$ $1, \ldots, n$. The estimated values of $u_{i}\left(a_{i}\right)$ are often referred to as part-worths or partial utilities.

The respondent evaluates some product profiles (typically between three and six at a time), which include feature levels defined in the study for choosing the best profile offered. In CBC analysis, the error term $\varepsilon$ has a Gumbel distribution (with a location parameter of zero and a variance of $\pi / 6)$. The Gumbel distribution is relatively similar to the normal distribution and is used because the choice probabilities can be expressed in a simple closed form formula, unlike the case of a normal distribution. The evaluation of alternative profiles with independent valuation errors results in the multinomial logit choice model (McFadden 1974; Swait and Louviere 1993): if $k$ product profiles with total values $V_{1}, \ldots$,
$V_{k}$ are compared, the probability $p_{l}$ that profile $l$ is chosen is

$p l=\frac{e^{V} l}{\sum_{S=1}^{k} e^{V_{S}}}$.

The estimation of the utility functions and aggregate or individual utilities are carried out by hierarchical Bayes estimation (HB). The HB uses Markov chain Monte Carlo (MCMC) simulations as a means of estimation and has proved to be very efficient (Halme and Kallio 2011). MCMC iterations in estimating the part-worths mean that starting from a priori part-worths, an a posteriori estimate is produced using sampling, and this process is repeated for a large number of iterations. The estimation is an iterative process, where after convergence, the estimates are calculated as the means of the last iterations when convergence already occurred.

In our case, the hierarchical Bayes (Sawtooth Software, HB 5.0) was used in the estimation. The Bayesian method for conducting the statistical test, which compares the importance scores of the features across the two groups, was employed. We ran the dataset with HB supplementing the choice data with a priori information of the type of player group for each respondent. That information is then used as a covariate in the HB estimation (see Orme and Howell 2009). The software produces draws of the a posteriori probability distribution for the difference in the average scores across the two groups. When viewing that distribution, if the confidence level is $95 \%$ (for the difference in averages to be positive), 95 of the observations were positive.

\section{Appendix 5}

Table 10 Screenshot of the research instrument

\begin{tabular}{|r|l|}
\hline $\begin{array}{r}\text { Usability } \\
\text { Enjoyment }\end{array}$ & $\begin{array}{l}\text { Difficult to use } \\
\text { Plain graphics, } \\
\text { sounds and } \\
\text { animations }\end{array}$ \\
Functionalities & $\begin{array}{l}\text { Comprehensive set } \\
\text { of functionalities } \\
\text { Poker network } \\
\text { Large number of } \\
\text { players } \\
\text { Loyalty program } \\
\text { Comphrehensive } \\
\text { loyalty program } \\
\text { Proven reputation }\end{array}$ \\
\hline & \\
\hline
\end{tabular}

Easy to use
Enjoyable graphics,
sounds and
animations
Only basic
functionalities
Limited number of
players
Limited loyalty
program
Proven reputation

\begin{tabular}{l} 
Difficult to use \\
Plain graphics, \\
sounds and \\
animations \\
Only basic \\
functionalities \\
Limited number of \\
players \\
Comphrehensive \\
loyalty program \\
No established \\
reputation record \\
\hline
\end{tabular}


Open Access This article is distributed under the terms of the Creative Commons Attribution 4.0 International License (http:// creativecommons.org/licenses/by/4.0/), which permits unrestricted use, distribution, and reproduction in any medium, provided you give appropriate credit to the original author(s) and the source, provide a link to the Creative Commons license, and indicate if changes were made.

\section{References}

Adler, P.A., \& Adler, P. (1999). Resort workers: Adaptations in the leisure-work Nexus. Sociological Perspectives, 42(3), 369-402.

Babin, B., Darden, W., Griffin, M., \& Darden, R. (1994). Work and/or Fun : Shopping Measuring Value Hedonic and Utilitarian. Journal of Consumer Research, 20(4), 644-656.

Bala, H., \& Venkatesh, V. (2007). Assimilation of Interorganizational business process standards. Information Systems Research, 18(3), $340-362$.

Batra, R., \& Ahtola, O. T. (1990). Measuring the hedonic and utilitarian sources of consumer attitudes. Marketing Letters, 2(2), 159-170.

Bhattacherjee, A. (2001). An empirical analysis of the antecedents of electronic commerce service continuance. Decision Support Systems, 32, 201-214.

Bolton, R., Kannan, P., \& Bramlett, M. (2000). Implications of loyalty program membership and service experiences for customer retention and value. Journal of the Academy of Marketing Science, 28(1), 95108.

Carr, N. (2003). IT doesn't matter. Harvard Business Review, May 2003, 41-49.

Chismar, W., \& Wiley-Patton, S. (2002). Test of the Technology Acceptance Model for the Internet Pediatrics. In AMIA Annual Symposium Proceedings (pp. 155-159).

Chitturi, R., Raghunathan, R., \& Mahajan, V. (2008). Delight by design: The role of delight hedonic versus utilitarian benefits. Journal of Marketing, 72(3), 48-63.

Chrzan, K., \& Orme, B. (2000). An overview and comparison of design strategies for choice-based conjoint analysis. WA: Sequim.

Davis, F. (1989). Perceived usefulness, perceived ease of use, and user acceptance of information technology. MIS Quaterly, 13(3), 319340.

Derikx, S., de Reuver, M., \& Kroesen, M. (2016). Can privacy concerns for insurance of connected cars be compensated? Electronic Markets, 26(1), 73-81.

Eastlick, M., Lotz, S., \& Warrington, P. (2006). Understanding online Bto-C relationships: An integrated model of privacy concerns, trust, and commitment. Journal of Business Research, 59(8), 877-886.

Eisenmann, T., Parker, G., \& Van Alstyne, M. (2006). Strategies for twosided markets. Harvard Business Review, 84(10), 92-101.

Eisenmann, T., Parker, G., \& Van Alstyne, M. (2011). Platform envelopment. Strategic Management Journal, 32(12), 1270-1285.

Farrell, J., \& Saloner, G. (1985). Standardization, compatibility, and innovation. The Rand Journal of Economics, 16(1), 70-83.

Gefen, D., Karahanna, E., \& Straub, D. W. (2003). Trust and TAM in online shopping: An integrated model. MIS Quarterly, 27(1), 51-90.

Gelman, A., Carlin, J., Stern, H., Dunson, D., Vehtari, A., \& Rubin, D. (2013). Bayesian data analysis, third edition. Boca Raton, FL: Chapman \& Hall/CRC.

Gerow, J., Ayyagari, R., Thatcher, J., \& Roth, P. (2013). Can we have fun @ work? The role of intrinsic motivation for utilitarian systems. European Journal of Information Systems, 22(3), 360-380.

Giessmann, A., \& Stanoevska-Slabeva, K. (2013). What are developers' preferences on platform as a service? An empirical investigation. In
Proceedings of the Annual Hawaii International Conference on System Sciences (pp. 1035-1044).

Green, P., Krieger, A., \& Wind, Y. (2001). Thirty Years of Conjoint Analysis: Reflections and Prospects. Interfaces, 31(3Supplement), 56-73.

Gu, J.-C., Fan, L., Suh, Y. H., \& Lee, S.-C. (2010). Comparing utilitarian and hedonic usefulness to user intention in multipurpose information systems. Cyberpsychology, Behavior, and Social Networking, 13(3), 287-297.

Hagiu, A., \& Eisenmann, T. (2007). A staged solution to the Catch-22. Harvard Business Review, 85(11), 25-26.

Haile, N., \& Altmann, J. (2016). Structural analysis of value creation in software service platforms. Electronic Markets, 26(2), 129-142.

Halme, M., \& Kallio, M. (2011). Estimation methods for choice-based conjoint analysis of consumer preferences. European Journal of Operational Research, 214(1), 160-167.

Hann, I.-H., Hui, K.-L., Lee, S.-Y., \& Png, I. (2007). Overcoming online information privacy concerns: An information-processing theory approach. Journal of Management Information Systems, 24(2), 13-42.

Hannum, R., \& Cabot, A. (2009). Toward legalization of poker: the skill vs. chance debate. UNLV Gaming Research \& Review Journal, 13(1), 1-20.

Hirschman, E., \& Holbrook, M. (1982). Hedonic consumption: Emerging concepts, methods and propositions. Journal of Marketing, 46(3), 92-101.

Hoffman, D., Novak, T., \& Peralta, M. (1999). Building consumer trust online. Communications of the ACM, 42(4), 80-85.

Hong, S., \& Tam, K. (2006). Understanding the adoption of multipurpose information appliances: The case of mobile data services. Information Systems Research, 17(2), 162-179.

Hsu, C.-L., \& Lin, J. (2008). Acceptance of blog usage: The roles of technology acceptance, social influence and knowledge sharing motivation. Information \& Management, 45, 65-74.

Johnson, F., Hauber, A., Osoba, D., Hsu, M., Coombs, J., \& CopleyMerriman, C. (2006). Are chemotherapy patients' HRQoL importance weights consistent with linear scoring rules? A stated-choice approach. Quality of Life Research, 15(2), 285-298.

Katz, M., \& Shapiro, C. (1985). Network externalities, competition and compatibility. The American Economic Review, 75(3), 424-440.

Katz, M., \& Shapiro, C. (1986). Technology adoption in the presence of network externalities. Journal of Political Economy, 94(4), 822, 841.

Keil, M., \& Tiwana, A. (2006). Relative importance of evaluation criteria for enterprise systems: A conjoint study. Information Systems Journal, 16(3), 237-262.

Kersten, G., \& Noronha, S. (1999). WWW-based negotiation support: Design, implementation, and use. Decision Support Systems, 25(2), 135-154.

Lee, J.-S., Cho, H., Gay, G., Davidson, B., \& Ingraffea, A. (2003). Technology acceptance and social networking in distance learning. Educational Technology \& Society, 6(2), 50-61.

Lee, M., Cheung, C., \& Chen, Z. (2005). Acceptance of internet-based learning medium: The role of extrinsic and intrinsic motivation. Information Management, 42, 1095-1104.

Li, H., Liu, Y., Xu, X., Heikkilä, J., \& Van Der Heijden, H. (2015). Modeling hedonic is continuance through the uses and gratifications theory: An empirical study in online games. Computers in Human Behavior, 48, 261-272.

Louviere, J., Flynn, T., \& Carson, R. (2010). Discrete choice experiments are not conjoint analysis. Journal of Choice Modelling, 3(3), 57-72.

Lowry, P., Gaskin, J., \& Hammer, B. (2013). Taking "fun and games" seriously: Proposing the hedonic-motivation system adoption model. Journal of the Association for Information Systems, 14(11), 617671. 
McCormack, A., \& Griffiths, M. (2012). What differentiates professional poker players from recreational poker players? A qualitative interview study. International Journal of Mental Health and Addiction, 10, 243-257.

McFadden, D. (1974). Conditional logit analysis of qualitative choice behavior. In P. Zarembka (Ed.), Frontiers in Econometrics (pp. 105-142). New York: Academic Press, Inc.

Merikivi, J., Tuunainen, V., \& Nguyen, D. (2017). What makes continued mobile gaming enjoyable? Computers in Human Behavior, 68, 411421.

Nielsen, J. (1993). Usability Engineering. Academic Press, Inc.

Orme, B., \& Howell, J. (2009). Application of covariates within Sawtooth Softwares $\mathrm{CBC} / \mathrm{HB}$ program: Theory and practical example Sawtooth software.

Park, Y., \& el Sawy, O. (2008). Towards a design theory for hedonic systems: Delivering superior user experience in the digital home entertainment context. In V. Vaishnavi \& R. Baskerville (Eds.), Proceedings of the third international conference on design science research in information systems and technology (pp. 323-328). Atlanta, Georgia.

Parker, G., \& Van Alstyne, M. (2005). Two-sided network effects: A theory of information product design. Management Science, 51(10), 1494-1504.

Parker, G., Van Alstyne, M., \& Choudary, S. (2016). Platform revolution: How Networked Markets Are Transforming the Economy-And How to Make Them Work for You. New York, NY: W.W. Norton \& Company Inc.

Penttinen, E., Halme, M., Lyytinen, K. \& Myllynen, N. (2018) What influences choice of business-to-business connectivity platforms? International Journal of Electronic Commerce, 22(4).

Phillips, K., Johnson, F., \& Maddala, T. (2002). Measuring what people value: A comparison of "attitude" and "preference" surveys. Health Services Research, 37(6), 1659-1679.

Salo, J., \& Karjaluoto, H. (2007). A conceptual model of trust in the online environment. Online Information Review, 31(5), 604-621.

Siau, K., Sheng, H., Nah, F., \& Davis, S. (2003). Development of a framework for Trust in Mobile Commerce. In Proceedings of the Second Annual Workshop on HCI Research in MIS, Seattle, WA, December 12-13, 2003 (pp. 85-89).

Sieroty, C. (2011). Panel says critical mass matters for online poker. Las Vegas Business Press, 20(20).

Soliman, W., \& Tuunainen, V. K. (2015). Understanding continued use of crowdsourcing systems: An interpretive study. Journal of
Theoretical and Applied Electronic Commerce Research, 10(1), 118.

Swait, J., \& Louviere, J. (1993). The role of the scale parameter in the estimation and comparison of multinomial logit models. Journal of Marketing Research, 30, 305-314.

Teichert, T., \& Shehu, E. (2010). Investigating research streams of conjoint analysis: A bibliometric study. Business Research, 3(1), 48-68.

Trenz, M. (2015). Multichannel Commerce - A Consumer Perspective on the Integration of Physical and Electronic Channels. Switzerland: Springer International Publishing.

Turel, O., Serenko, A., \& Bontis, N. (2010). User acceptance of hedonic digital artifacts: A theory of consumption values perspective. Information Management, 47(1), 53-59.

van der Heijden, H. (2004). User acceptance of hedonic information systems. MIS Quarterly, 28(4), 695-704.

Verhagen, T., Feldberg, F., Van Den Hooff, B., Meents, S., \& Merikivi, J. (2012). Understanding users' motivations to engage in virtual worlds: A multipurpose model and empirical testing. Computers in Human Behavior, 28(2), 484-495.

Vilén, V. (2013). Choosing a website to play poker - A comparison between utilitarian and hedonic users, MSC thesis, Aalto University School of Business.

Voss, K., Spangenberg, E., \& Grohmann, B. (2003). Measuring the Hedonic and Utilitarian Dimensions of Consumer Attitude. Journal of Marketing Research, XL(August 2003), 159-170.

Weiss, T., \& Schiele, S. (2013). Virtual worlds in competitive contexts: Analyzing eSports consumer needs. Electronic Markets, 23, 307316.

Wood, R., Williams, R., \& Lawton, P. (2007). Why do internet gamblers prefer online versus land-based venues? Some preliminary findings and implications. Journal of Gambling Issues, 20, 235-252.

Wu, J. (2014). Customer satisfaction in the context of online gaming service: The hedonic experience factor. International Journal of Business Analytics, 1(3), 63-80.

Wu, J., Li, P., \& Rao, S. (2008). Why they enjoy virtual game worlds? An empirical investigation. Journal of Electronic Commerce Research, 9(3), 219-230.

Wu, J., \& Lu, X. (2013). Effects of extrinsic and intrinsic motivators on using utilitarian, hedonic, and dual-purposed information systems: A meta-analysis. Journal of the Association for Information Systems, 14(3), 153-191. 